\title{
Persistent cortisol response to desmopressin predicts recurrence of Cushing's disease in patients with post-operative corticotropic insufficiency
}

\author{
S Cambos' ${ }^{1}$, K Mohammedi', F Castinetti ${ }^{3}$, C Saie ${ }^{4}$, J Young ${ }^{4,5,6}$, P Chanson ${ }^{4,5,6}$ and A Tabarin ${ }^{1,2}$
}

${ }^{1} \mathrm{CHU}$ Bordeaux, Hôpital Haut-Lévêque, Service d'Endocrinologie, Diabétologie et Nutrition, Pessac, France, ${ }^{2}$ INSERM and University of Bordeaux Neurocentre Magendie, Bordeaux, France, ${ }^{3}$ Department of Endocrinology, Aix Marseille University, Marseille Medical Genetics, INSERM, and Assistance Publique-Hopitaux de Marseille, French Reference Center for Rare Pituitary Diseases, Marseille, France, ${ }^{4}$ Assistance Publique-Hôpitaux de Paris, Hôpitaux Universitaires Paris-Saclay, Hôpital de Bicêtre, Service d'Endocrinologie et des Maladies de la Reproduction, Le Kremlin Bicêtre, France, ${ }^{5}$ Université Paris Saclay, Univ Paris-Sud, Faculté de Médecine Paris-Sud, UMR-S1185, Le Kremlin Bicêtre, France, and ${ }^{6}$ INSERM 1185, Fac Med Paris Sud, Université Paris-Saclay, Le Kremlin-Bicêtre, France

Correspondence should be addressed to A Tabarin Email antoine.tabarin@chubordeaux.fr

\begin{abstract}
Objective: Cushing's disease (CD) may recur despite corticotropic insufficiency (COI) following pituitary surgery. The predictive value of the desmopressin test (DT) for recurrence in this setting remains controversial. We have evaluated whether the disappearance of the response to DT predicts a low probability recurrence in a large cohort of patients with post-operative COI.

Design: Multicentre retrospective study.

Methods: Ninety-five patients with CD (women $82 \%$, age $41 \pm 14$ years), responding preoperatively to DT and with early post-operative COI (08 00 am cortisol: $<138 \mathrm{nmol} / \mathrm{L}$ ), underwent a DT within 3 months post-surgery. Association between DT findings and the prediction of recurrence was tested using regression and ROC analyses.

Results: Recurrence occurred in 17/95 patients within 29 to 91 months. The cortisol peak (327, 95\% Cl (237-417) vs 121 (79-164) nmol/L, $P=0.0001)$ and absolute increment during DT (208 (136-280) vs $56(22-90) \mathrm{nmol} / \mathrm{L}, P=0.005)$ were greater in the recurrence vs remission group. Cortisol peak (AUC: $0.786(0.670-0.902))$ and increment $(0.793(0.672-$ 0.914)) yielded a higher prognostic performance for recurrence than did the early post-operative 0800 am cortisol (0.655 (0.505-0.804)). In the context of COI, cortisol peak $>100 \mathrm{nmol} / \mathrm{L}$ and increment $>30 \mathrm{nmol} / \mathrm{L}$ had a high negative predictive value $(94,95 \% \mathrm{Cl}(88-100)$ and $94,(88-100)$, respectively). Patients with a cortisol peak $\leq 100 \mathrm{nmol} / \mathrm{L}$ (vs $>100$ ) or an increment $\leq 30 \mathrm{nmol} / \mathrm{L}$ ( $\mathrm{vs}>30$ ) were less likely to have $\mathrm{CD}$ recurrence (odds ratios: $0.12,95 \% \mathrm{Cl}(0.03-0.41$ ) and $0.11(0.02-0.36)$, respectively).

Conclusion: The disappearance of the response to the post-operative DT was independently associated with a lower odds of CD recurrence and offers an incremental prognostic value, which may help to stratify patients with COI and refine their follow-up according to the risk of recurrence.
\end{abstract}

European Journal of Endocrinology

(2020) 182, 489-498
Published by Bioscientifica Ltd. 


\section{Introduction}

Transphenoidal Surgery (TSS) is the recommended firstline therapeutic option for Cushing's disease (CD). However, despite post-operative remission, recurrence of the disease occurs in 5 to $47 \%(1,2,3)$. Therefore, life-long follow-up is recommended for all patients, (3).

Given the median reported rate of recurrence, a systematic follow-up for all patients implies that approximately $2 / 3$ of patients in post-operative remission will have avoidable examinations and tests that can lead to both unnecessary cost and possibly to increased stress. Various biological parameters have been studied to predict the risk of recurrence and define groups at highand low risk for whom the duration and frequency of follow-up examinations could differ $(4,5,6,7)$. Although controversy persists with regard to the threshold concentrations of plasma cortisol, the most commonly admitted prognostic factor for long-term remission is an early post-operative corticotropic insufficiency (COI) (1, $3,7,8,9$ ), defined by the Endocrine Society as an 0800 am cortisol concentration $\leq 138 \mathrm{nmol} / \mathrm{L}$ (2). However, recurrence may still occur in 12 to $26 \%$ patients with postoperative COI, emphasizing the need for other prognostic factors $(9,10,11,12)$.

Desmopressin is a synthetic analog of vasopressin, specific for the vasopressin V2 receptor (V2R) that is physiologically absent in pituitary corticotrophs. By contrast, adenomatous corticotrophs may aberrantly express the V2R (13), and a 'paradoxical' in vivo increase in plasma cortisol and ACTH is observed following desmopressin injection in 82 to $100 \%$ of patients with CD $(14,15)$. Several studies have evaluated the desmopressin test (DT) as a prognostic tool for post-operative recurrence of $\mathrm{CD}$, based on the assumption that a response reflects the persistence of adenomatous cells that will lead to recurrence of the disease $(7,16,17,18,19,20,21,22)$. Published studies suffer from various methodological limitations. These include the limited size of cohorts $(17,18,19)$; short duration of follow-up (17), which inherently reduces the number of recurrences $(17,18)$; and limited statistical power to detect the investigated associations. The criteria used to diagnose post-operative remission and recurrence are also sometimes debatable (17), or imprecise $(20,21,22)$, leading to potential bias in the classification of patients according to their endocrine status. Methodological concerns also apply to the DT, including an arbitrary definition of response (16), delayed timing of the test following surgery (20), and a lack of pre-operative evaluation of patients with the test $(7,18,21)$, a condition that favours the inclusion of patients who are non-responders and thereby reduces the capacity of the test to predict recurrence.

Consequently, we retrospectively evaluated whether DT predicts CD outcomes in a large cohort of patients with confirmed post-operative COI and who were followed over a long period.

\section{Patients and methods}

\section{Patients}

An extensive retrospective search for $\mathrm{CD}$ patients was conducted in two University Hospitals (CHU) in France between 1998 and 2018 (Bordeaux Hospital and Kremlin Bicêtre Hospital). The data were collected under conditions of regular clinical care and patients gave their consent to participate in the study. The use of the data was approved by the local ethics committee of Bordeaux CHU. This study was possible since these two endocrine departments followed the same procedure for investigating patients with ACTH-dependent $\mathrm{CD}$ and suspected of $\mathrm{CD}$ over many years. Among the other usual investigations, this included a pre-operative desmopressin test, evaluation of post-operative $0800 \mathrm{am}$ plasma cortisol within 7 days following TSS, and a desmopressin test during the early post-operative period. In addition, data from 11 patients from the University Hospital La Conception (Marseille, France), which was included in a prior study and satisfied the criteria described, were included in the present study after updating the patient follow-up data (7). Diagnosis of CD was based on the combination of overt clinical Cushing's syndrome, biochemical assessment, confirmatory histology, and/or occurrence of corticotropic insufficiency following pituitary surgery (23).

To be included in the study, patients were required to fulfil the following criteria:

1. Have a paradoxical response to the pre-operative desmopressin test according to our locally established criteria (see subsequent section),

2. Have undergone TSS,

3. Have an early post-operative COI, defined according to the recommendation of the Endocrine Society as an08 00 am serum cortisol $<138 \mathrm{nmol} / \mathrm{L}(5 \mu \mathrm{g} / \mathrm{L})$ within 7 days following TSS (3) and after at least an 18-h withdrawal of hydrocortisone supplementation,

4. Be evaluated with a post-operative desmopressin test within 3 months following TSS (median: $7(6,30)$ days), and

5. Have been followed for at least 12 months. 


\section{Follow-up}

According to the current practice of each center, patients were seen every 3 to 6 months during the period of COI following TSS. A detailed analysis of the hypothalamicpituitary-adrenal axis function was performed at the time of recovery from COI. Patients in remission were then regularly followed at $6-12$ months intervals. Biochemical evaluation, performed at each evaluation to screen for recurrence, varied and included a clinical examination by an expert endocrinologist and at least one biochemical investigation such as 24-h urinary free cortisol (UFC), LNSC, or $1 \mathrm{mg}$ dexamethasone suppression test (DST).

Persistent remission at the end of follow-up was defined as the lack of recurrent clinical symptoms and association of at least two of the following biochemical criteria: normal 24-h UFC, cortisol suppression after $1 \mathrm{mg}$ DST $(<50 \mathrm{nmol} / \mathrm{L})$, and normal LNSC concentration.

Recurrence of CD was defined as the reappearance of clinical symptoms of hypercortisolism after examination by an expert endocrinologist and at least one of the following biochemical tests being abnormal: consistently increased UFC, increased LNSC, or non-suppressibility of cortisol after $1 \mathrm{mg}$ DST (3).

\section{Desmopressin test}

After an overnight fast and at least 18-h withdrawal of hydrocortisone supplementation, subjects were administered a $10 \mu \mathrm{g}$ desmopressin injection (Minirin ${ }^{\circledR}$ parenteral solution, Ferring laboratories, Milano, Italy). Consecutive samples of cortisol and ACTH were collected before injection (baseline sample=T0) and after 15, 30, 45,60 , and 90 min as previously described (24).

To determine the threshold for the positivity of the preoperative $\mathrm{DT}$, we used the results of a specific prospective study conducted in Bordeaux hospital involving 68 patients (age: $42.0 \pm 15.8$ years, $\mathrm{F} / \mathrm{M}$ ratio $=5.8$ ) with an active $\mathrm{CD}$ and a control group of 56 patients. Among these, 28 patients with depression, truncal obesity associated with eating disorders and/or PCOS, and alcoholism had functional non-neoplastic hypercortisolism, 18 patients had a non-corticotropic pituitary adenoma, and 10 were overweight/obese subjects. Using the receiver operator characteristic (ROC) analyses, a combined criterion based on an absolute ACTH increase over baseline $\geq 27 \mathrm{pg} / \mathrm{mL}$ and/or an absolute cortisol increment $\geq 106 \mathrm{nmol} / \mathrm{L}$ was chosen to define a paradoxical response during the DT, consistent with the diagnosis of $\mathrm{CD}$.

\section{Measurements}

Radioimmunoassays (RIAs), Chemiluminescence immunoassays (CLIAs), and Liquid Chromatograpy using mass spectrometry (LC--MS) were used over the study period in endocrine reference laboratories of each center to measure plasma and urinary cortisol and ACTH concentrations. UFC concentrations were analyzed by comparison with normal ranges used in each center. Details on all assay methods are listed in Supplementary data (see section on supplementary materials given at the end of this article). In patients with undetectable concentrations of plasma cortisol and ACTH, a value corresponding to the detection limit of the assay (see Supplementary data) was used for statistical purposes.

\section{Statistical analysis}

Continuous variables are expressed as mean \pm S.D. or median (25th, 75th percentiles) for those variables with a skewed distribution. Categorical variables are presented as number of patients with corresponding percentage. Characteristics of participants with CD recurrence vs those with sustained remission during follow-up were compared using chi-squared, ANOVA, or Wilcoxon tests. Variables with skewed distribution were log-transformed for statistical analyses. Limited data were missing (Table 1), they were not imputed, and were excluded from the analyses.

Linear regression analysis was used to test associations between hormonal parameters during the desmopressin test (baseline, peak, and absolute increment (peak minus baseline) of cortisol and ACTH concentrations) and the likelihood of $\mathrm{CD}$ recurrence in univariable and multivariable models. Adjustment was performed for gender, age at diagnosis, and immediate post-operative $0800 \mathrm{am}$ plasma cortisol concentrations (model 1). Furthermore, we tested the multiplicative interaction between the early post-operative 0800 am cortisol and various hormonal responses during the test on their association with $\mathrm{CD}$ recurrence. Hence, we have introduced the 'early postoperative 0800 am cortisol x each hormonal response' during the DT into the regression model.

We also conducted a sensitivity analysis to assess associations between various criteria for response to the desmopressin test and the likelihood of CD recurrence after adjustment for baseline desmopressin cortisol (for cortisol analyses) or ACTH concentrations (for ACTH analyses) 
Table 1 Characteristics of participants according to CD recurrence status. Categorial variables are expressed as frequency (percentage) and continuous variables as median (25th, 75th percentiles), except for age, presented as mean \pm S.D.

\begin{tabular}{|c|c|}
\hline & Missing data \\
\hline \multicolumn{2}{|l|}{$n(\%)$} \\
\hline \multicolumn{2}{|l|}{ Age at diagnosis (years) } \\
\hline Mean \pm S.D. & 0 \\
\hline $95 \% \mathrm{Cl}$ & 0 \\
\hline Women, $n(\%)$ & 0 \\
\hline Macro-/micro-adenomas $(n)$ & 3 \\
\hline Pre-operative 24 h UFC (xULN) & 0 \\
\hline Pre-operative ACTH (pg/mL) & 5 \\
\hline Duration of follow-up (months) & 6 \\
\hline
\end{tabular}

\begin{tabular}{c}
\hline All \\
\hline 95 \\
$41.0 \pm 13.9$ \\
$38.2-43.9$ \\
$78(82)$ \\
$18 / 74$ \\
$2.0(1.7-2.9)$ \\
$59(39-81)$ \\
$61(29-91)$ \\
\hline
\end{tabular}

\begin{tabular}{c}
\hline Remission \\
\hline $78(82)$ \\
$42.5 \pm 13.6$ \\
$39.4-45.5$ \\
$63(81)$ \\
$15 / 61$ \\
$2.0(1.7-2.8)$ \\
$59(38-80)$ \\
$54(24-91)$ \\
\hline
\end{tabular}

\begin{tabular}{c}
\hline Recurrence \\
\hline $17(18)$ \\
$34.5 \pm 13.9$ \\
$27.3-41.6$ \\
$15(88)$ \\
$3 / 13$ \\
$2.0(1.5-4.1)$ \\
$60(42-84)$ \\
$82(48-106)$ \\
\hline
\end{tabular}

\begin{tabular}{c} 
P value \\
\hline \\
0.03 \\
\\
0.73 \\
0.93 \\
0.72 \\
0.59 \\
0.13
\end{tabular}

Comparisons were performed using $\mathrm{Chi}^{2}$, Wilcoxon, or ANOVA test. $P$-value $<0.05$ was considered as significant.

$C D$, Cushing's disease; ULN, upper limit of normal range.

Sensitivity, specificity, and positive (PPV) and negative predictive value (NPV) were computed and areas under the curve (AUC) with associated 95\% CI were plotted, using ROC analyses, to compare the prognostic values of different hormonal criteria of response to the desmopressin test vs the early postoperative 0800 -h cortisol concentrations for the prediction of $\mathrm{CD}$ recurrence. To determine patients with low likelihood for $\mathrm{CD}$ recurrence, we selected the cut-off allowing the best compromise between specificity and sensitivity associated with a high NPV. A logistic regression model was used to test the association between the selected cut-offs and low CD recurrence, expressed as odds ratio with related $95 \%$ CI.

Statistical analyses were performed using JMP 14 SW software (SAS Institute, www.sas.com) and Stata software version 13 (StataCorp, www.stata.com). Two-sided $P$-values less than 0.05 were considered as significant.

\section{Results}

\section{Characteristics of participants at time of study inclusion}

Two hundred and thirty-two patients with CD were followed after pituitary TSS. Of these, 128 participants were pre-selected based on a positive pre-operative DT (as defined previously). Thirty-three participants were excluded because of early post-operative plasma $0800 \mathrm{am}$ cortisol concentrations $>138 \mathrm{nmol} / \mathrm{L}$. Thus, 95 patients with post-operative COI were included in the current study (Fig. 1). Eighteen and 74 patients had corticotropic macroadenomas and microadenomas, respectively. The patients were mainly women $(82 \%)$, the mean age was $41.0 \pm 13.9$ years, and they were followed for a median duration of 61 (29-91) months.

Seventeen patients (18\%) experienced a recurrence of CD after $30(15,60)$ months following TSS (recurrence group), while 78 patients (82\%) were still in remission at the end of the follow-up period (remission group). All patients diagnosed with a recurrence of $\mathrm{CD}$ required an additional treatment of $\mathrm{CD}$. Pre-operative characteristics of patients are depicted in Table 1. Patients in the remission group were older than those in the recurrence group $(42.5 \pm 13.6$ vs $34.5 \pm 13.9$ years, $P=0.03)$. The main hormonal characteristics and type of adenoma were comparable between groups, including the duration of follow-up: 54 (24-91) months in the remission group and $82(48-106)$ months in the recurrence group, respectively $(P=0.13)$.

\section{Pre-operative desmopressin test according to recurrence status}

The results of the desmopressin test performed before TSS are presented in Supplementary Table 1. No difference was observed between the two groups of patients in terms of baseline, peak, and absolute increment of cortisol and ACTH concentrations during the desmopressin test.

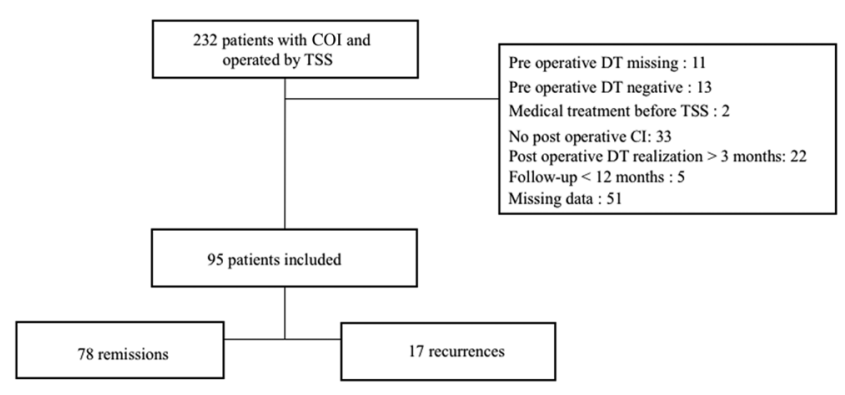

Figure 1

Flow chart. CD, Cushing's Disease; TSS, Transsphenoidal Surgery; COI: Corticotropic insufficiency; DT: Desmopressin test. 


\section{Post-operative desmopressin test according to recurrence status}

Although all patients had COI, the mean early postoperative plasma 0800 am cortisol was increased in participants with recurrence of $\mathrm{CD}$ compared to those with sustained remission: $63 \pm 39$ vs $44 \pm 29 \mathrm{nmol} / \mathrm{L}$ (median (25th, 75th percentiles), $29(25,52)$ vs 25 (19, 33)); $P=0.03$. This association remained significant after adjustment for sex and age $(P=0.002)$. The results of the DT in patients of the recurrence and remission groups are presented in Fig. 2 and Table 2. Compared to patients in the remission group, those in the recurrence group had increased cortisol and ACTH concentrations in different desmopressin test settings (baseline concentrations, peak concentration, and absolute increment) in the univariable model. The peak and absolute increment of cortisol remained significantly increased in the recurrence group compared to the remission group in the multi-variable analysis. Significant associations between baseline and ACTH peaks during the DT and the recurrence of CD also persisted after adjustment for confounding variables. No significant interaction between the early post-operative 0800 am cortisol and cortisol or ACTH concentrations during the different DT settings were observed (all $P$-values for interaction $>0.05$ ).

\section{Sensitivity analyses}

To test the independence (of their association with the recurrence of $\mathrm{CD}$ ) between the baseline values on one hand and the peak and increment during the test on the
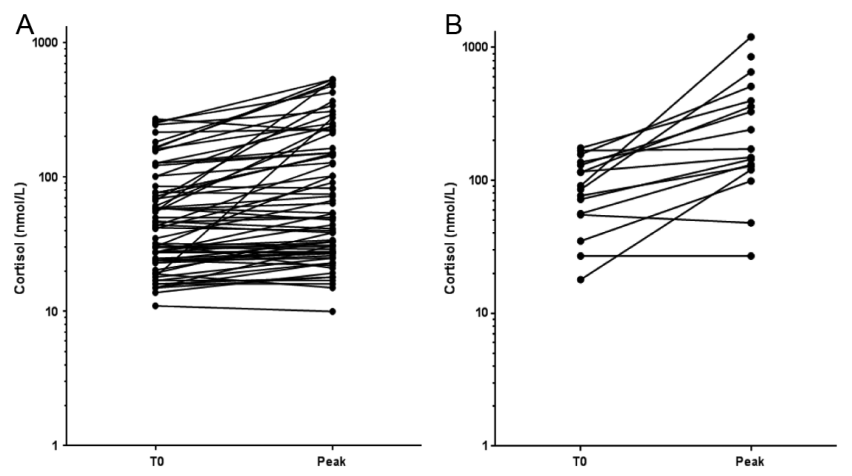

\section{Figure 2}

Individual cortisol responses to the desmopressin test. (A) Patients in persistent remission of Cushing's disease. (B) Patients with recurrence of Cushing's disease during the follow-up. $\mathrm{T0}$ = plasma cortisol concentration before the injection of desmopressin. other hand, we included the baseline value in the multiadjusted model. The cortisol peak and absolute increment remained significantly associated with recurrence after adjustment for baseline cortisol during the test, while the ACTH peak-recurrence association disappeared after adjustment for baseline ACTH (Supplementary Table 2). However, the association between the ACTH peak and recurrence completely disappeared after adjustment for the cortisol peak (22.8 (16.3-29.3) vs $20.6(4.4-36.8)$ $\mathrm{pg} / \mathrm{mL}$ in remission and recurrence groups, respectively, $P=0.91$ ).

\section{Prognostic value of the post-operative desmopressin test for the prediction of CD outcome following surgery}

The AUC (95\% CI) using ROC analyses to determine the prognostic values of plasma concentrations of early postoperative 0800 am cortisol concentrations and the different hormonal criteria of the post-operative desmopressin test are displayed in Table 3 and plotted in Fig. 3. The peak of cortisol during the DT predicted recurrence of CD significantly better than did the early post-operative 0800 am cortisol level $(0.786(0.670-0.902)$ vs 0.655 (0.505-0.804), $P=0.04$ ) (Fig. 3A and Table 3).

A strong trend toward improvement in the prediction of $\mathrm{CD}$ recurrence was also observed with the absolute cortisol increment (Fig. 3C and Table 3). No significant improvement in the prediction of $\mathrm{CD}$ recurrence was observed with the other criteria of the DT (Fig. 3 and Table 3).

Cut-offs and related specificities, sensitivities, and PPV and NPV of the early post-operative $0800 \mathrm{am}$ cortisol, the peak of cortisol, and the absolute cortisol increment during the DT are presented in Table 4 . An early post-operative 08 00 am cortisol $>50 \mathrm{nmol} / \mathrm{L}$, cortisol peak $>100 \mathrm{nmol} / \mathrm{L}$, and absolute cortisol increment $>30 \mathrm{nmol} / \mathrm{L}$ during the post-operative DT were the best compromise between specificity and sensitivity for the prediction of recurrence (Table 4). The $100 \mathrm{nmol} / \mathrm{L}$ and $30 \mathrm{nmol} / \mathrm{L}$ cutoffs for the cortisol peak and absolute increment, respectively, yielded the best NPV.

In the context of COI, the cortisol peak (>100 vs $\leq 100$ $\mathrm{nmol} / \mathrm{L}$ ) predicted recurrence better than did early postoperative $0800 \mathrm{am}$ cortisol (>50 vs $\leq 50 \mathrm{nmol} / \mathrm{L}$ ): AUC $0.758(0.657-0.857)$ vs $0.600(0.460-0.734), P<0.0001$. Also, the absolute increment of cortisol ( $>30$ vs $\leq 30$ $\mathrm{nmol} / \mathrm{L}$ ) yielded a better prognostic performance than the early post-operative 0800 am cortisol cut-off ( $>50$ vs $\leq 50$ $\mathrm{nmol} / \mathrm{L})$ : AUC 0.771 (0.671-0.870), $P<0.04$. 
Table 2 Analysis of the post-operative desmopressin test according to CD recurrence status. Data presented as mean ( $95 \% \mathrm{Cl}$ ). Comparisons performed using linear regression analyses in univariable and multivariable models.

\begin{tabular}{l}
\hline $\begin{array}{l}\text { Concentration during the } \\
\text { desmopressin test }\end{array}$ \\
\hline Cortisol (nmol/L) \\
Baseline \\
Peak \\
Increment \\
ACTH (pg/mL) \\
Baseline \\
Peak \\
Increment
\end{tabular}

\begin{tabular}{|c|c|c|}
\hline \multicolumn{3}{|c|}{ Univariable model } \\
\hline Remission & Recurrence & $P$ \\
\hline $66(52-81)$ & 95 (64-126) & 0.01 \\
\hline $121(79-164)$ & 327 (237-417) & 0.0001 \\
\hline $56(22-90)$ & $208(136-280)$ & 0.005 \\
\hline $11.3(9.1-13.5)$ & $19.0(14.4-23.7)$ & 0.008 \\
\hline $21.5(14.7-28.4)$ & $42.2(27.9-56.6)$ & 0.001 \\
\hline $10.3(4.6-16.0)$ & $23.6(11.6-35.6)$ & 0.04 \\
\hline
\end{tabular}

\begin{tabular}{|c|c|c|}
\hline \multicolumn{3}{|c|}{ Multivariable model* } \\
\hline Remission & Recurrence & $P$ \\
\hline $72(58-86)$ & $91(61-121)$ & 0.08 \\
\hline $138(93-183)$ & $313(221-406)$ & 0.001 \\
\hline $62(28-96)$ & $196(118-275)$ & 0.01 \\
\hline $10.6(8.3-13.0)$ & $19.0(14.1-23.8)$ & 0.02 \\
\hline $22.5(15.0-30.0)$ & $41.1(25.7-56.5)$ & 0.01 \\
\hline $11.1(5.3-16.9)$ & $21.9(8.7-35.1)$ & 0.32 \\
\hline
\end{tabular}

*Adjustment for gender, age at diagnosis of CD (Cushing's disease), and early post-operative 0800 am cortisol (model 1). Cortisol and ACTH values were log-transformed for generating $P$-values. $P$-value $<0.05$ was considered as significant.

Patients with a cortisol peak during the DT $\leq 100$ $\mathrm{nmol} / \mathrm{L}$ (vs $>100$ ) or an increment $\leq 30 \mathrm{nmol} / \mathrm{L}$ (vs $>30$ ) were less likely to have CD recurrence: odds ratios (95\% CI) $0.12(0.03-0.41), P=0.0004$ and $0.11(0.02-0.36)$, $P=0.0002$, respectively. However, patients with an early post-operative $0800 \mathrm{am}$ cortisol ( $<50 \mathrm{vs} \geq 50 \mathrm{nmol} / \mathrm{L})$ did not have a significantly lower likelihood of $\mathrm{CD}$ recurrence: odds ratio $0.45(0.15-1.37), P=0.15$.

\section{Discussion}

The present study demonstrates that a persistent paradoxical postoperative response to DT is a significant early prognostic biomarker for the recurrence of $\mathrm{CD}$ in patients with postoperative COI. Our results show a strong and consistent association between the peak and increment of cortisol during the DT and the recurrence of $\mathrm{CD}$. These associations were independent of confounding variables including age, sex, and early post-operative 0800 am cortisol. No significant interaction was observed between the early post-operative $0800 \mathrm{am}$ cortisol and the cortisol response during the test on their association with $\mathrm{CD}$ recurrence. Importantly, the association between the cortisol response and recurrence was statistically independent of the baseline cortisol concentration during the DT.

For subjects with COI, the cortisol response during the DT had a higher prognostic value than the early postoperative 0800 am cortisol concentration for predicting the recurrence of $\mathrm{CD}$. This greatest prognostic value was consistent when we considered the cortisol response both as a quantitative variable or a categorical trait (based on the best compromise of combination between specificity and sensitivity). Interestingly, a cortisol peak $\leq 100 \mathrm{nmol} / \mathrm{L}$ (vs $>100 \mathrm{nmol} / \mathrm{L}$ ) or cortisol increment $\leq 30$ (vs $>30 \mathrm{nmol} / \mathrm{L}$ ) was associated with a lower odds of $\mathrm{CD}$ recurrence.

Our study further expands on the results of previous studies, since all of the major methodological

Table 3 Comparison of the prognostic values between the post-operative desmopressin test and the early post-operative 0800 am cortisol for the prediction of CD recurrence. Data are presented as area under the curve (AUC) and $95 \% \mathrm{Cl}$ computed using the receiver operator characteristic (ROC) analyses.

\begin{tabular}{|c|c|c|}
\hline & AUC $(95 \% \mathrm{Cl})$ & $P$ value \\
\hline Early post-operative 0800 am cortisol & $0.655(0.505-0.804)$ & Reference \\
\hline \multicolumn{3}{|l|}{ Concentration during the desmopressin test } \\
\hline \multicolumn{3}{|l|}{ Cortisol } \\
\hline Baseline & $0.709(0.571-0.848)$ & 0.26 \\
\hline Peak & $0.786(0.670-0.902)$ & 0.04 \\
\hline Increment & $0.793(0.672-0.914)$ & 0.07 \\
\hline \multicolumn{3}{|l|}{ ACTH } \\
\hline Baseline & $0.701(0.544-0.859)$ & 0.61 \\
\hline Peak & $0.740(0.608-0.872)$ & 0.24 \\
\hline Increment & $0.726(0.580-0.871)$ & 0.44 \\
\hline
\end{tabular}

$P$-values were computed for the comparison of AUCs between cortisol concentrations during the desmopressin test (baseline, peak, or increment) and early post-operative $0800-\mathrm{h}$ cortisol (Reference). $P<0.05$ considered as significant. $\mathrm{CD}$, Cushing's disease. 

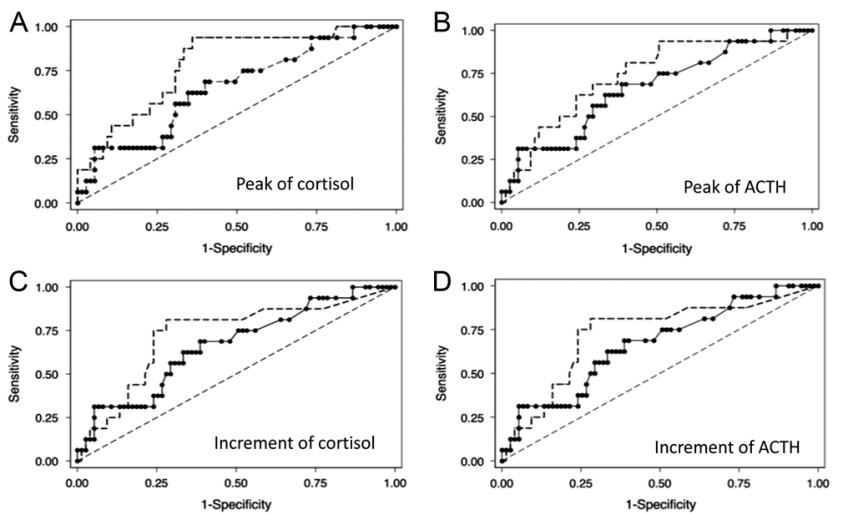

Figure 3

Receiver operator characteristic curves comparing the prediction of $C D$ recurrence during the desmopressin test (dashed line) vs the early post-operative 0800 am cortisol (solid line). (A) Peak of cortisol; (B) Peak of ACTH; (C) Increment of cortisol; (D) Increment of ACTH. CD: Cushing's disease.

requirements for ensuring the reliability of results are satisfied. The use of unquestionable reference standards for an accurate classification of patients is of primary importance. Contrary to our study that used an accepted criterion of COI (early post-operative 0800 am cortisol $<138 \mathrm{nmol} / \mathrm{L}$ ) (2), various combinations of criteria, sometimes debatable, have been used in previous studies that could have resulted in the erroneous inclusion of eucortisolic patients, for example, patients at a higher risk of recurrence, in the remission group.

Elsewhere it has been shown that the responsiveness to the DT can be an early biomarker of recurrence (20, 25 , 26), a specific purpose that is different from the scope of our study. The timing of the test, for example, during the transient phase of COI, is important to differentiate between the predictive value for recurrence and the early diagnosis of recurrence. Delayed timing of the test, by up to 6 months post-operatively in several studies, and analysis of the baseline cortisol during the test in some of these $(19,21)$ suggests that a number of patients had already recovered from COI, a situation that may cause some confusion between the predictive and diagnostic performances of the test. In addition, it should be emphasized that all patients in our study, who were diagnosed with recurrence, required additional treatment for CD, information that is rarely provided in published studies and that strengthens this diagnosis. As the rationale of the post-operative DT is to demonstrate the persistent presence of a small amount of adenomatous remnants, selection of patients harboring adenomatous corticotrophs responsive to the test is another important

Table 4 Sensitivity, specificity, and positive and negative predictive values of plasma concentrations of cortisol for the prediction of $C D$ recurrence. Cut-offs, and related sensitivities, specificities, and positive and negative predictive values (with associated $95 \% \mathrm{Cl}$ ) were computed using the receiver operator characteristic analyses.

\begin{tabular}{|c|c|c|c|c|}
\hline Cut-off (nmol/L) & Sensitivity $(95 \% \mathrm{Cl})$ & Specificity $(95 \% \mathrm{Cl})$ & $\begin{array}{l}\text { Positive predictive } \\
\text { value }(95 \% \mathrm{Cl})\end{array}$ & $\begin{array}{c}\text { Negative predictive } \\
\text { value }(95 \% \mathrm{Cl})\end{array}$ \\
\hline \multicolumn{5}{|c|}{ Early post-operative 0800 am cortisol } \\
\hline$>20$ & $100(82-100)$ & $13(10-27)$ & $19(11-28)$ & $93(81-100)$ \\
\hline$>30$ & 75 (54-96) & $43(34-57)$ & $22(11-33)$ & $90(80-99)$ \\
\hline$>50$ & $56(26-75)$ & $69(58-79)$ & $25(10-40)$ & $87(78-95)$ \\
\hline$>70$ & $31(9-54)$ & $83(75-91)$ & $28(7-48)$ & 85 (77-93) \\
\hline$>100$ & $31(4-46)$ & $95(90-99)$ & $50(15-85)$ & $86(78-93)$ \\
\hline$>120$ & $13(1-29)$ & $96(92-100)$ & $40(1-83)$ & $84(76-92)$ \\
\hline \multicolumn{5}{|c|}{ Peak of cortisol concentration during the desmopressin test } \\
\hline$>27$ & $100(83-100)$ & $19(11-29)$ & $21(12-30)$ & $94(82-100)$ \\
\hline$>55$ & $88(73-100)$ & $53(43-66)$ & $31(18-44)$ & $95(89-100)$ \\
\hline$>100$ & $88(64-100)$ & $64(53-75)$ & $34(20-49)$ & $94(88-100)$ \\
\hline$>150$ & $58(29-77)$ & $73(63-83)$ & $31(14-48)$ & $87(79-96)$ \\
\hline$>220$ & $47(23-71)$ & $80(71-89)$ & $35(15-54)$ & $87(79-95)$ \\
\hline$>500$ & $24(3-44)$ & $95(92-100)$ & $57(20-94)$ & $85(77-92)$ \\
\hline \multicolumn{5}{|c|}{ Absolute increment of cortisol concentration during the desmopressin test } \\
\hline$>5$ & $82(64-99)$ & $45(34-57)$ & $25(14-37)$ & $92(83-99)$ \\
\hline$>10$ & $83(64-99)$ & $55(43-66)$ & $29(16-42)$ & $93(86-99)$ \\
\hline$>30$ & $82(64-100)$ & $67(56-77)$ & $36(21-51)$ & $94(88-100)$ \\
\hline$>50$ & $76(56-97)$ & $72(62-82)$ & $38(22-55)$ & $93(87-99)$ \\
\hline$>100$ & $47(23-71)$ & $83(74-91)$ & $38(17-59)$ & 87 (80-95) \\
\hline$>300$ & $23(3-44)$ & 95 (80-99) & $50(15-85)$ & 85 (77-92) \\
\hline
\end{tabular}


pre-requisite. Inclusion of non-responding patients during the active phase of $\mathrm{CD}$ is likely to limit the predictive performance of the test. In this study, we carefully selected patients based on the results of the preoperative DT after establishing our own criteria for responsiveness using appropriate control groups. Therefore, a strength of our study is to satisfy the various crucial methodological criteria to evaluate the predictive performance of the test for the outcome of $\mathrm{CD}$ in patients with confirmed early post-operative COI. Lastly, another strength of our study is the size of the cohort, which includes a significant number of recurrences, thereby providing an adequate statistical power for the study. Interestingly, the $18 \%$ recurrence rate within a median of 30 months in our study is comparable to published reports of patients with COI $(10,11,22)$.

Some authors have advocated the analysis of ACTH concentrations during the test, rather than cortisol concentrations. Indeed, baseline and peak ACTH during the DT were also associated with the recurrence of $\mathrm{CD}$, but these associations were inconsistent and dependent on confounding variables, particularly when adjusted for cortisol peak or baseline ACTH (Table 2). Compared to the immediate post-operative 0800 am cortisol concentration, the ACTH results during the DT did not provide any incremental prognostic improvement for the prediction of CD recurrence (Fig. 3).

As previously reported by Romanholi et al. (22) and Vassiliadi et al. (19), we also found that the cortisol increment was associated with the recurrence of $\mathrm{CD}$. In our study, the cortisol increment during the test was associated with $\mathrm{CD}$ recurrence in the principal multiadjusted model and tended to be significantly associated after further adjustment for baseline cortisol under the test (Supplementary Table 2). Last, the cortisol increment tended to improve the prediction of $\mathrm{CD}$ recurrence although such association reached bordeline statistical significance.

Overall, cortisol peak and increment yielded comparable information, but their combination did not result in additive prognostic value (data not shown). Both criteria had their respective caveats. Some patients had baseline cortisol $\geq 100 \mathrm{nmol} / \mathrm{L}$ before injection of desmopressin. For these subjects, the use of the cortisol increment may be more relevant. On the opposite, $15 \%$ of patients in our series had undetectable plasma cortisol. In this situation, the limit of detection of the assay was used for calculation purposes. However, this widely accepted procedure induces some bias in the calculation of the true cortisol increment.

Some published studies have suggested that a more stringent criterion for COI (e.g. post-operative plasma cortisol concentration $<50 \mathrm{nmol} / \mathrm{L}$ ) better predicts longterm remission $(1,7,9,27,28)$. We also observed that, within the spectrum of COI, the lowest post-operative cortisol concentrations were associated with a lower rate of recurrence. However, in our study, a $50 \mathrm{nmol} / \mathrm{L}$ cut-off for 0800 am cortisol measured within 7 days following surgery had lower NPV for recurrence than the cortisol peak and increment (87, 94, and 94; respectively). Moreover, highest early post-operative cortisol concentrations within the range of COI $(>50 \mathrm{nmol} / \mathrm{L}$ vs $\leq 50 \mathrm{nmol} / \mathrm{L})$ were not predictive of $\mathrm{CD}$ recurrence, while a cortisol peak $>100 \mathrm{nmol} / \mathrm{L}(\mathrm{vs} \leq 100)$ and increment $>30 \mathrm{nmol} / \mathrm{L}$ (vs $\leq 30$ ) were associated with significant improvement in prediction of $\mathrm{CD}$ recurrence.

A pathophysiological hypothesis may explain the better prognostic performance of the DT as compared to early post-operative cortisol concentrations, since these two investigations assess different processes: while cortisol concentrations reflect the spontaneous activity of adenomatous and, hypothetically, non-adenomatous corticotrophs, the DT directly assesses only the presence of residual adenomatous corticotrophs. Contrary to the DT, it is conceivable that the level of post-operative cortisol and the intensity of post-operative COI may be influenced by a number of factors that are not involved in recurrence, such as the intensity and duration of previous hypercortisolism as well as the individual sensitivity of normal pituitary tissue to cortisol excess. An evident limitation of the DT is its ability to detect only residual adenomatous cells that aberrantly express the V2R (13), emphasizing the importance of pre-operative testing. Moreover, and despite its significant prognostic value, it should be emphasized that the prediction of recurrence is still a probabilistic approach, since $18 \%$ of our patients who had recurrence did not exhibit an early response to the DT.

Our study has some limitations although we tried to fit with TRIPOD guidelines for prognostic tool evaluation (Supplementary Table 3). Despite being performed in consecutive patients, the study suffers from its retrospective design and inherent selection bias. However, our two study groups were well balanced - all participants displayed COI according to a robust definition; the results of the pre-operative DT were similar between groups; and the characteristics of participants at study inclusion were comparable, except for age. It is also noteworthy that our findings remained significant after adjustment for age. The duration of the study is also a limitation and we cannot exclude that some patients classified as in remission will experience a later recurrence, resulting 
in an overestimation of the NPV of the test. Importantly, our findings and thresholds for the cortisol response need external validation, ideally in a prospective study with extended follow-up. Finally, as is the case in any study, the thresholds for cortisol and ACTH concentrations quoted here may not be strictly applicable to other centres using different assays.

In conclusion, our study demonstrates that the DT is able to identify a subgroup of patients within patients with COI who are at low risk of recurrence, at least in the mid-term, and is an independent and significantly better prognostic biomarker than early post-operative cortisol concentrations. Long-term recurrence may still occur in patients not responding to the test, a finding that supports the recommendation of life-long follow-up in all patients operated for CD. However, due to reduced probability of recurrence, the frequency and intensity of follow-up procedures may be reduced in patients with COI who show a disappearance of the response to the DT, thereby reducing the cost of superfluous investigations and the stress of excessive follow-up in susceptible individuals. Whether follow-up investigations in the two groups of patients could differ, for example, LNSC in responsive patients $(4,26)$ or repetition of the DT in patients with a negative post-operative test $(25,29,30)$, remains to be studied.

\section{Supplementary materials}

This is linked to the online version of the paper at https://doi.org/10.1530/ EJE-19-0770.

\section{Declaration of interest}

The authors declare that there is no conflict of interest that could be perceived as prejudicing the impartiality of this study.

\section{Funding}

This work did not receive any specific grant from any funding agency in the public, commercial, not-for-profit sector or industry.

\section{References}

1 Petersenn S, Beckers A, Ferone D, van der Lely A, Bollerslev J, Boscaro M, Brue T, Bruzzi P, Casanueva FF, Chanson P et al. Therapy of endocrine disease: outcomes in patients with Cushing's disease undergoing transsphenoidal surgery: systematic review assessing criteria used to define remission and recurrence. European Journal of Endocrinology 2015172 R227-R239. (https://doi.org/10.1530/EJE-140883)

2 Nieman LK, Biller BMK, Findling JW, Murad MH, Newell-Price J, Savage MO, Tabarin A \& Endocrine Society. Treatment of Cushing's syndrome: an Endocrine Society clinical practice guideline. Journal of
Clinical Endocrinology and Metabolism 2015100 2807-2831. (https:// doi.org/10.1210/jc.2015-1818)

3 Tritos NA, Biller BMK \& Swearingen B. Management of Cushing disease. Nature Reviews: Endocrinology 20117 279-289. (https://doi. org/10.1038/nrendo.2011.12)

4 Amlashi FG, Swearingen B, Faje AT, Nachtigall LB, Miller KK, Klibanski A, Biller BMK \& Tritos NA. Accuracy of late-night salivary cortisol in evaluating postoperative remission and recurrence in Cushing's disease. Journal of Clinical Endocrinology and Metabolism 2015100 3770-3777. (https://doi.org/10.1210/jc.2015-2107)

5 Lindsay JR, Oldfield EH, Stratakis CA \& Nieman LK. The postoperative basal cortisol and CRH tests for prediction of long-term remission from Cushing's disease after transsphenoidal surgery. Journal of Clinical Endocrinology and Metabolism 201196 2057-2064. (https://doi.org/10.1210/jc.2011-0456)

6 Alwani RA, de Herder WW, van Aken MO, van den Berge JH, Delwel EJ, Dallenga AHG, De Jong FH, Lamberts SWJ, Van der Lely AJ $\&$ Feelders RA. Biochemical predictors of outcome of pituitary surgery for Cushing's disease. Neuroendocrinology 201091 169-178. (https://doi.org/10.1159/000258677)

7 Le Marc'hadour P, Muller M, Albarel F, Coulon AL, Morange I, Martinie M, Gay E, Graillon T, Dufour H, Conte-Devoix B et al. Postoperative follow-up of Cushing's disease using cortisol, desmopressin and coupled dexamethasone-desmopressin tests: a head-to-head comparison. Clinical Endocrinology 201583 216-222. (https://doi.org/10.1111/cen.12739)

8 Pereira AM, van Aken MO, van Dulken H, Schutte PJ, Biermasz NR, Smit JWA, Roelfsema F \& Romjin JA. Long-term predictive value of postsurgical cortisol concentrations for cure and risk of recurrence in Cushing's disease. Journal of Clinical Endocrinology and Metabolism 200388 5858-5864. (https://doi.org/10.1210/jc.2003-030751)

9 Patil CG, Prevedello DM, Lad SP, Vance ML, Thorner MO, Katznelson L \& Laws ER. Late recurrences of Cushing's disease after initial successful transsphenoidal surgery. Journal of Clinical Endocrinology and Metabolism 200893 358-362. (https://doi. org/10.1210/jc.2007-2013)

10 Yap LB, Turner HE, Adams CB \& Wass JA. Undetectable postoperative cortisol does not always predict long-term remission in Cushing's disease: a single centre audit. Clinical Endocrinology 200256 25-31. (https://doi.org/10.1046/j.0300-0664.2001.01444.x)

11 Chandler WF, Barkan AL, Hollon T, Sakharova A, Sack J, Brahma B \& Schteingart DE. Outcome of transsphenoidal surgery for Cushing disease: a single-center experience over 32 years. Neurosurgery 2016 78 216-223. (https://doi.org/10.1227/NEU.0000000000001011)

12 Biller BMK, Grossman AB, Stewart PM, Melmed S, Bertagna X, Bertherat J, Buchfelder M, Colao A, Hermus AR, Hofland LJ et al. Treatment of adrenocorticotropin-dependent Cushing's syndrome: a consensus statement. Journal of Clinical Endocrinology and Metabolism 200893 2454-2462. (https://doi.org/10.1210/jc.2007-2734)

13 Wang F-F, Tang K-T, Yen Y-S, Ho DM-T, Yang A-H, Huang C-I, Hwang C-I, Lin H-D \& Won JGS. Plasma corticotrophin response to desmopressin in patients with Cushing's disease correlates with the expression of vasopressin receptor 2, but not with that of vasopressin receptor 1 or 3, in their pituitary tumours. Clinical Endocrinology 2012 76 253-263. (https://doi.org/10.1111/j.1365-2265.2011.04179.x)

14 Terzolo M, Reimondo G, Alì A, Borretta G, Cesario F, Pia A, Pacotti P \& Angeli A. The limited value of the desmopressin test in the diagnostic approach to Cushing's syndrome. Clinical Endocrinology 200154 609-616. (https://doi.org/10.1046/j.13652265.2001.01260.x)

15 Vassiliadi DA \& Tsagarakis S. DIAGNOSIS of ENDOCRINE DISEASE: The role of the desmopressin test in the diagnosis and follow-up of Cushing's syndrome. European Journal of Endocrinology $2018 \mathbf{1 7 8}$ R201-R214. (https://doi.org/10.1530/EJE-18-0007)

16 Losa M, Bianchi R, Barzaghi R, Giovanelli M \& Mortini P. Persistent adrenocorticotropin response to desmopressin in the early 
postoperative period predicts recurrence of Cushing's disease. Journal of Clinical Endocrinology and Metabolism 200994 3322-3328. (https:// doi.org/10.1210/jc.2009-0844)

17 Colombo P, Dall'Asta C, Barbetta L, Re T, Passini E, Faglia G \& Ambrosi B. Usefulness of the desmopressin test in the postoperative evaluation of patients with Cushing's disease. European Journal of Endocrinology 2000143 227-234. (https://doi.org/10.1530/ eje.0.1430227)

18 Valero R, Vallette-Kasic S, Conte-Devolx B, Jaquet P \& Brue T. The desmopressin test as a predictive factor of outcome after pituitary surgery for Cushing's disease. European Journal of Endocrinology 2004 151 727-733. (https://doi.org/10.1530/eje.0.1510727)

19 Vassiliadi DA, Balomenaki M, Asimakopoulou A, Botoula E, Tzanela $\mathrm{M} \&$ Tsagarakis $\mathrm{S}$. The desmopressin test predicts better than basal cortisol the long-term surgical outcome of Cushing's disease. Journal of Clinical Endocrinology and Metabolism 2016101 4878-4885. (https://doi.org/10.1210/jc.2016-2799)

20 Ambrogio AG, Andrioli M, De Martin M, Cavagnini F \& Pecori Giraldi F. Usefulness of desmopressin testing to predict relapse during long-term follow-up in patients in remission from Cushing's disease. Endocrine Connections 20176 791-799. (https://doi.org/10.1530/ EC-17-0292)

21 Barbot M, Albiger N, Koutroumpi S, Ceccato F, Frigo AC, Manara R, Fassina A, Gardiman MP, Scanarini M, Mantero F et al. Predicting late recurrence in surgically treated patients with Cushing's disease. Clinical Endocrinology 201379 394-401. (https://doi.org/10.1111/ cen.12133)

22 Romanholi DJPC, Machado MC, Pereira CC, Danilovic DS, Pereira MAA, Cescato VAS, Cunha Neta MB, Musolino NRC, de Mendonça BB \& Salgado LR. Role for postoperative cortisol response to desmopressin in predicting the risk for recurrent Cushing's disease. Clinical Endocrinology 200869 117-122. (https://doi. org/10.1111/j.1365-2265.2007.03168.x)

23 Nieman LK, Biller BMK, Findling JW, Newell-Price J, Savage MO, Stewart PM \& Montori VM. The diagnosis of Cushing's syndrome: an Endocrine Society Clinical Practice Guideline. Journal of Clinical
Endocrinology and Metabolism 200893 1526-1540. (https://doi. org/10.1210/jc.2008-0125)

24 Losa M, Mortini P, Dylgjeri S, Barzaghi R, Franzin A, Mandelli C \& Giovanelli M. Desmopressin stimulation test before and after pituitary surgery in patients with Cushing's disease. Clinical Endocrinology 200155 61-68. (https://doi.org/10.1046/j.13652265.2001.01324.x)

25 Bou Khalil R, Baudry C, Guignat L, Carrasco C, Guibourdenche J, Gaillard S, Bertagna X \& Bertherat J. Sequential hormonal changes in 21 patients with recurrent Cushing's disease after successful pituitary surgery. European Journal of Endocrinology 2011165 729-737. (https:// doi.org/10.1530/EJE-11-0424)

26 Danet-Lamasou M, Asselineau J, Perez P, Vivot A, Nunes ML, Loiseau H, San-Galli F, Cherifi-Gatta B, Corcuff JB \& Tabarin A. Accuracy of repeated measurements of late-night salivary cortisol to screen for early-stage recurrence of Cushing's disease following pituitary surgery. Clinical Endocrinology 201582 260-266. (https:// doi.org/10.1111/cen.12534)

27 Ironside N, Chatain G, Asuzu D, Benzo S, Lodish M, Sharma S, Nieman L, Stratakis CA, Lonser RR \& Chittiboina P. Earlier postoperative hypocortisolemia may predict durable remission from Cushing's disease. European Journal of Endocrinology 2018178 255-263. (https://doi.org/10.1530/EJE-17-0873)

28 Trainer PJ, Lawrie HS, Verhelst J, Howlett TA, Lowe DG, Grossman AB, Savage MO, Afshar F \& Besser GM. Transsphenoidal resection in Cushing's disease: undetectable serum cortisol as the definition of successful treatment. Clinical Endocrinology $1993 \mathbf{3 8}$ 73-78. (https://doi.org/10.1111/j.1365-2265.1993.tb00975.x)

29 Dall'Asta C, Barbetta L, Bonavina L, Beck-Peccoz P \& Ambrosi B. Recurrence of Cushing's disease preceded by the reappearance of ACTH and cortisol responses to desmopressin test. Pituitary 20047 183-188. (https://doi.org/10.1007/s11102-005-0425-9)

30 Ambrosi B, Malavazos AE, Passeri E \& Dall'Asta C. Desmopressin test may predict the risk of recurrence in Cushing's disease. Clinical Endocrinology 200970 811. (https://doi.org/10.1111/j.13652265.2008.03406.x)

Received 27 September 2019

Revised version received 13 February 2020

Accepted 18 March 2020 